\title{
Perfluorooctanoic Acid Enhances Invasion of Follicular Thyroid Carcinoma Cells Through NF-kB and Matrix Metalloproteinase-2 Activation
}

\author{
PIPOP SAEJIA $^{1}$, KRIENGSAK LIRDPRAPAMONGKOL ${ }^{2}$, \\ JISNUSON SVASTI ${ }^{1,2}$ and N. MONIQUE PARICHARTTANAKUL ${ }^{2}$ \\ ${ }^{1}$ Applied Biological Sciences Program, Chulabhorn Graduate Institute, \\ Chulabhorn Royal Academy, Bangkok, Thailand; \\ ${ }^{2}$ Laboratory of Biochemistry, Chulabhorn Research Institute, Bangkok, Thailand
}

\begin{abstract}
Background/Aim: Perfluorooctanoic acid (PFOA) is one of the most common perfluorinated compounds widely used in several applications. Due to its persistence in the environment, PFOA has been associated with various diseases, including cancer. This study explored the effects of PFOA on follicular thyroid carcinoma cells (FTC133). Materials and Methods: Cell invasion, migration, adhesion and activity of matrix metalloproteinase-2 (MMP2) were investigated using Transwell assays, adhesion assay and gelatin zymography, respectively. The underlying mechanism involved in the effects observed was evaluated by immunoblot analyses. Results: Treatment with PFOA did not affect cell migration, but enhanced cell invasion, adhesion and activity of MMP-2 in FTC133 cells. PFOA selectively enhanced the phosphorylation of nuclear factor kappa $B$ $(N F-k B) \quad p 65$, as well as induced $N F-k B$ nuclear translocation. Treatment with a NF-kB inhibitor (BAY 117085) was able to reverse PFOA-induced cell invasiveness. Conclusion: PFOA promotes invasiveness of FTC133 cells mediated through the activation of $N F-k B$ signaling.
\end{abstract}

Perfluorooctanoic acid (PFOA) is the main member of a group of perfluorinated compounds, which have recently received increased attention for their potential health consequences in humans. PFOA is a synthetic chemical substance that is composed of an aliphatic eight-carbon backbone with all the hydrogen atoms substituted with fluorine to form strong C-F bonds, and a charged carboxyl

Correspondence to: Dr. N. Monique Paricharttanakul, Laboratory of Biochemistry, Chulabhorn Research Institute, 54 Kamphaeng Phet 6 Road, Laksi, Bangkok 10210, Thailand. Tel: +66 25538555 ext. 8348, e-mail: nilubol@ cri.or.th

Key Words: PFOA, MMP-2, invasion, NF-kB, follicular thyroid cancer. group. PFOA is produced in relatively large amounts for commercial purposes and used in several applications such as industrial and consumer processes for stain- and waterresistant coatings, oil-resistant coatings for paper products, firefighting foams, mining and oil well surfactants, as well as in insecticide formulations (1).

The hydrophobic, lipophilic and non-polar properties of PFOA make it more persistent in the environment, becoming a global pollutant of air, water and soil $(2,3)$. The average daily uptake of PFOA in humans is in the range of 1.1 to $11.6 \mathrm{ng} / \mathrm{kg} \mathrm{BW} /$ day (4). PFOA is readily absorbed, binds to proteins in blood serum and accumulates mainly in organs such as the liver, kidney, spleen, testicles and brain (2). The renal clearances of PFOA are almost negligible in humans with an estimated half-life in blood serum of 3.8 years (5). The median PFOA levels in sera of the general US population are 4 to $5 \mathrm{ng} / \mathrm{ml}$ (approximately 9.6-12.0 nM) (6).

Exposure to PFOA can lead to changes in cancer cell metastasis and thereby contribute to enhanced aggressiveness of cancer. Metastasis is a multi-step process that occurs when tumor cells leave the primary tumor and spread to distant organs (7), and appears to be a major factor leading to death of cancer patients. Exposure to PFOA has been reported to enhance migration and invasion in human Ishikawa endometrial cancer cells through the activation of ERK/MTOR signaling (8). Moreover, PFOA has been shown to promote cancer cell invasion via nuclear factor-kappaB (NF-kB) pathway in both breast and colorectal cancer cells (9, 10). Recently, PFOA was detected in several human tissues, including endocrine glands, such as thyroid, pituitary, gonads, and pancreas (11). PFOA has also been detected in surgical thyroid tissue specimens from patients undergoing thyroidectomy for a wide spectrum of thyroid diseases (12). In addition, PFOA has been shown to enter thyroid cells by a gradient-based passive diffusion mechanism (13). Therefore, exposure to PFOA may be a factor that promotes the progression of thyroid cancer. 
In this study, we investigated the biological effects of PFOA treatment on the invasiveness of follicular thyroid cancer cells, demonstrating that PFOA contributed to enhanced invasiveness of follicular thyroid carcinoma (FTC133) cells. The role of nuclear factor kappaB (NF-kB) on the PFOA-promoted cancer invasion was also elucidated. This knowledge should improve understanding of the linkage between exposure to an environmental contaminant and thyroid cancer progression.

\section{Materials and Methods}

Chemicals. PFOA (purity 95.0-102.0\% (Titration)) was purchased from FUJIFILM Wako Pure Chemical Corporation (Osaka, Japan). Specific NF-kB inhibitor (BAY 11-7085) was purchased from Calbiochem (San Diego, CA, USA).

Cell culture. Human follicular thyroid carcinoma (FTC133) cell line was kindly provided by Prof. Johan Lillehaug, University of Bergen, Norway. Cells were cultured in a 1:1 mixture of DMEM: Ham's F12 media (Gibco, NY, USA) supplemented with $10 \%$ fetal bovine serum (FBS), 1\% antibiotic-antimycotic solution, and $2 \mathrm{mM} \mathrm{L}-$ glutamine (Gibco). Cells were maintained at $37^{\circ} \mathrm{C}$ in $5 \% \mathrm{CO}_{2}$.

Cell invasion and migration assays. Invasion and migration assays were performed, as previously described (14) using Transwell chambers with $8 \mu \mathrm{m}$ pore size membrane filter (Costar, MA, USA). Briefly, the upper surface of the filter was coated with Matrigel (30 $\mu \mathrm{g}$ of Matrigel/filter) for invasion assays, while uncoated filters were used for migration assays. Chambers were incubated overnight at $37^{\circ} \mathrm{C}$ for gelling. FTC133 cells were treated with $1 \mathrm{nM}$ PFOA for $72 \mathrm{~h}$. At the end of the treatment, cells were detached and subjected to the assay. Cell suspensions of FTC133 cells $\left(2.5 \times 10^{4}\right.$ cells $\left./ \mathrm{ml}\right)$ in culture media containing $10 \%$ FBS were seeded into the inserts of Transwell chambers $(200 \mu \mathrm{l} /$ insert $)$. The same culture media were added to the lower chambers $(500 \mu \mathrm{l} /$ chamber $)$. The chambers were incubated for $24 \mathrm{~h}$ at $37^{\circ} \mathrm{C}$. After incubation, non-invading or nonmigrating cells on the upper surface of the filters were removed by wiping, using cotton swabs. The filters were then fixed with $25 \%$ methanol and stained with $0.5 \%(\mathrm{w} / \mathrm{v})$ crystal violet in $25 \%$ methanol. The number of invaded or migrated cells was counted for 5 fields/filter, at a magnification of $100 \times$ under an inverted microscope (Nikon T5100, Tokyo, Japan).

Cell adhesion assay. FTC133 cells were treated with $1 \mathrm{nM}$ PFOA for $72 \mathrm{~h}$. Cells were detached and seeded onto Matrigel-coated 96well plates $(10 \mu \mathrm{g}$ Matrigel/well $)$ at a density of $2 \times 10^{4}$ cells/well. Cells were allowed to attach for $1 \mathrm{~h}$ at $37^{\circ} \mathrm{C}$ before washing with PBS to remove non-attached cells. The number of attached cells was determined by MTT assay, as previously described (14).

Gelatin zymography. MMP-2 and MMP-9 are gelatinase enzymes that are usually secreted into the condition media. FTC133 cells were treated with $1 \mathrm{nM}$ PFOA for $72 \mathrm{~h}$. Cells were washed twice with serum-free media and further incubated in serum-free media for 24 $\mathrm{h}$. Then, the condition media were collected and subjected to gelatin zymography, as previously described (15). Briefly, $1 \mu \mathrm{g}$ condition media were electrophoresed in $7.5 \%$ SDS-polyacrylamide gel containing $1 \mathrm{mg} / \mathrm{ml}$ gelatin under non-reducing condition. Gels were rinsed with $2.5 \%$ Triton $\mathrm{X}-100$ to remove SDS prior to incubation in a buffer (50 mM Tris-HCL (pH 7), $5 \mathrm{mM} \mathrm{CaCl}_{2}, 1 \mu \mathrm{M} \mathrm{ZnCl}_{2}, 0.05 \%$ $\mathrm{NaN}_{3}$ ), for $16 \mathrm{~h}$ at $37^{\circ} \mathrm{C}$. Gels were stained with $0.3 \%$ Coomassie Brilliant Blue in $30 \% \mathrm{MeOH}$ and $10 \%$ acetic acid, and subsequently destained with $30 \% \mathrm{MeOH}$ and $10 \%$ acetic acid. Gelatinolytic activity of MMP-2 and MMP-9 should be observed as clear bands of digested gelatin on a dark background. The molecular mass of the band at $72 \mathrm{kDa}$ and $92 \mathrm{kDa}$ corresponds to the molecular mass of MMP-2 and MMP-9, respectively.

Protein extraction and immunoblot analysis. Effects of PFOA treatment on the expression levels of signaling proteins were analyzed by immunoblot analysis, as previously described (14). FTC133 cells were treated with $1 \mathrm{nM}$ PFOA for $72 \mathrm{~h}$ and then proteins were extracted. In order to determine the effect of the NF-kB inhibitor, cells were treated with $1 \mu \mathrm{M}$ BAY $11-7085$ for $1 \mathrm{~h}$ prior to PFOA treatment. Cells were lysed in RIPA lysis buffer containing protease inhibitor cocktail and phosphatase inhibitors $\left(1 \mathrm{mM} \mathrm{Na}_{3} \mathrm{VO}_{4}, 10 \mathrm{mM}\right.$ $\mathrm{NaF}$, and $20 \mathrm{mM} \beta$-glycerophosphate). Cell lysates were sonicated and cell debris removed by centrifugation at $12,000 \times \mathrm{g}$ for $5 \mathrm{~min}$, at $4^{\circ} \mathrm{C}$. The supernatants of cell lysates were collected and mixed with $5 \times$ sample loading buffer $(0.5 \mathrm{mM}$ Tris- $\mathrm{HCl} \mathrm{pH} 6.8,20 \%$ glycerol, $10 \%$ SDS, $0.1 \%$ bromophenol blue, and $5.0 \% \beta$-mercaptoethanol), followed by denaturation by boiling for $5 \mathrm{~min}$ and storage at $-80^{\circ} \mathrm{C}$. Total protein concentration of each cell lysate was measured by using Bradford protein assay (Bio-Rad, CA, USA).

Proteins $(15 \mu \mathrm{g})$ in the cell lysate were resolved in $10 \%$ SDSPAGE at $10 \mathrm{~mA} / \mathrm{gel}$ for approximately $60 \mathrm{~min}$, and blotted onto PVDF membranes at $100 \mathrm{~V}, 4^{\circ} \mathrm{C}$ for $60 \mathrm{~min}$. Then, the membranes were washed with Tris-buffered saline, $\mathrm{pH} 7.6$, containing $0.1 \%$ (v/v) Tween-20 (TBS/T). Membranes were blocked with 3\% bovine serum albumin (BSA) in TBS/T for $1 \mathrm{~h}$ at room temperature, and subsequently incubated with specific rabbit primary antibodies against total Akt $(1: 3,000)$, phospho-Akt (S473) $(1: 1,000)$, total Erk1/2 (1:2,000), phospho-Erk1/2 (T202/Y204) (1:2,000), total STAT3 $(1: 1,000)$, phospho-STAT3 (Y705) $(1: 1,000)$, total NF-kB p65 $(1: 1,000)$ and phospho-NF-kB p65 (S536) $(1: 1,000)$ (Cell Signaling Technology, MA, USA) overnight at $4^{\circ} \mathrm{C}$. The membranes were then washed with $\mathrm{TBS} / \mathrm{T}$, followed by incubation with horseradish peroxidase-linked anti-rabbit secondary antibody (Cell Signaling Technology) for $1 \mathrm{~h}$ at room temperature. Membranes were washed three times with TBS/T and then incubated with Western Bright ECL reagents (Advansta, CA, USA) for $5 \mathrm{~min}$. Bands of specific proteins were visualized by using ImageQuant LAS 4000 mini (GE Healthcare, WI, USA). Band intensity of the phosphorylated form of each protein was normalized to that of the total protein.

$N F-k B$ nuclear translocation assay. FTC133 cells were seeded onto 96-well plates and treated with $1 \mathrm{nM}$ PFOA for $72 \mathrm{~h}$. Cells were washed with phosphate buffered saline (PBS), fixed by immersion at room temperature with $4 \%$ paraformaldehyde for $10 \mathrm{~min}$ at $4{ }^{\circ} \mathrm{C}$, and permeabilized with blocking buffer (3\% BSA, $0.2 \%$ Triton$\mathrm{X} 100$ in PBS) for $45 \mathrm{~min}$ at $4^{\circ} \mathrm{C}$. Cells were then washed with PBS and incubated with primary monoclonal rabbit anti-NF-kB p65 in blocking buffer overnight at $4{ }^{\circ} \mathrm{C}$, followed by incubation with antirabbit secondary Alexa Fluor(R) 488 (Cell Signaling Technology) and Hoechst cell nuclear counter staining in blocking buffer for 45 min at room temperature. Subsequently, cells were washed with blocking buffer, followed by washing with PBS. Plates were imaged 
at 20x magnification on ImageXpress Micro XLS High Content Screening System (Molecular Devices, CA, USA) using FITC and DAPI channels.

Statistical analysis. Data were calculated from at least three independent experiments and presented as mean \pm SD. Differences between treated and untreated control cells were analyzed by using Student's $t$-test in Graph-Pad Prism 5 software (GraphPad Software, Inc., CA, USA). Data were considered significantly different when $p$-values were less than 0.05 .

\section{Results}

Effects of PFOA treatment on metastatic processes of follicular thyroid cancer cells. In order to investigate the ability of FTC133 cells to metastasize, cells were treated with $1 \mathrm{nM}$ of PFOA for $72 \mathrm{~h}$, followed by cell invasion, cell migration, and cell adhesion assays, as well as gelatin zymography of MMP-2 and MMP-9. PFOA enhanced the invasiveness of FTC133 cells by up to $145 \%$, when compared to that of the untreated control. However, the ability of FTC133 cells to migrate did not significantly change after treatment with PFOA. Results from cell adhesion assay showed that PFOA significantly increased the adhesion of FTC133 cells by up to $118 \%$, when compared to the untreated control cells. Since the process of cell invasion involves degradation of extracellular matrix (ECM), we explored the effects of PFOA on MMP-2 and MMP-9 activities, using gelatin zymography assay. The results using $1 \mu \mathrm{g}$ of loaded protein showed clear bands at the molecular weight of $66 \mathrm{kDa}$ corresponding to active MMP-2. After $72 \mathrm{~h}$ treatment with PFOA, MMP-2 activity was significantly increased up to $140 \%$, which suggested its involvement in the promotion of cancer cell invasion (Figure 1). However, MMP-9 activity was not detected at $92 \mathrm{kDa}$ and barely detectable even at a higher protein concentration (data not shown).

Effects of PFOA on invasion-related signaling pathways in FTC133 cells. Immunoblotting studies were used to investigate several intracellular signaling pathways that may be responsible for cancer cell invasion, including those involving protein kinase B (Akt), extracellular signalregulated kinases (ERK), activator of transcription 3 (STAT3) and nuclear factor kappa B (NF-kB) signaling, as well as the role of PFOA in enhancing FTC133 cell invasion. Protein lysates were extracted from FTC133 cells after treatment with $1 \mathrm{nM}$ PFOA and subjected to western blotting to measure the levels of expression of each signaling protein. Alterations in the expression of signaling proteins were detected after $72 \mathrm{~h}$ incubation (Figure 2A). Results showed that treatment with PFOA significantly increased the levels of phosphorylation of NF-kB p65, without affecting phosphorylation of Akt, ERK, and STAT3 (Figure 2B).

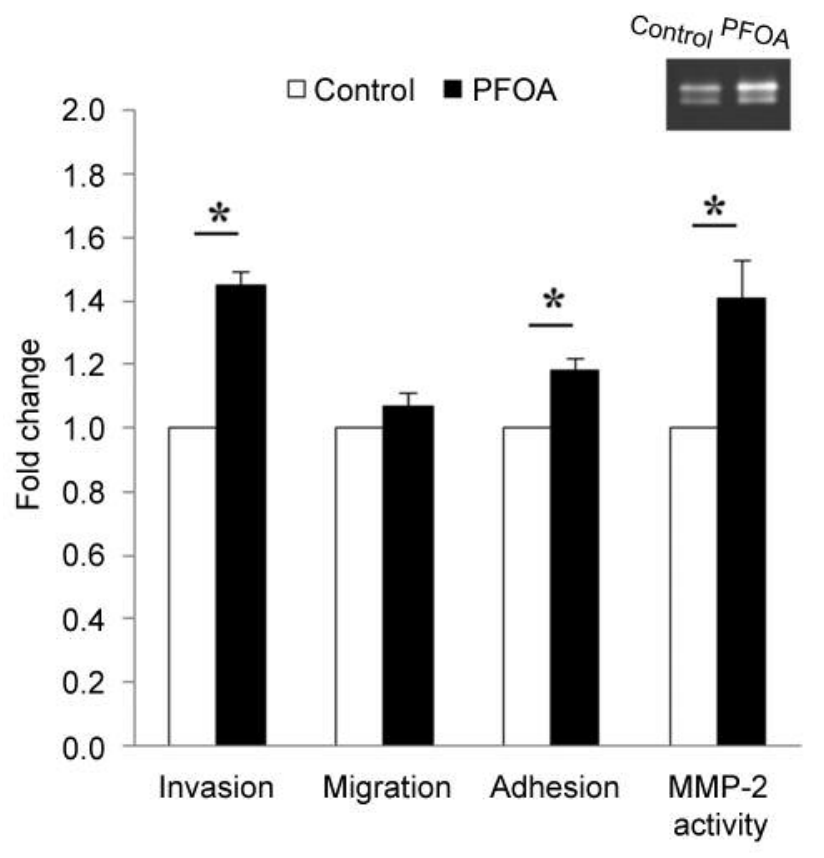

Figure 1. Effects of PFOA on the metastasis of FTC133 cells. Cells treated with $1 \mathrm{nM}$ PFOA or without PFOA for $72 \mathrm{~h}$ were assayed for cell migration, cell adhesion and cell invasion capability, as well as gelatin zymography of MMP-2. Inset shows the zymogram of MMP-2 activity upon treatment. Data are presented as mean $\pm S D$ in fold change of three independent experiments. ${ }^{*} p<0.05$.

Effects of PFOA on nuclear translocation of $N F-k B$ in FTC133 cells. Translocation of NF-kB is a critical step in the transcriptional activation of specific target genes. Upon cell stimulation, the nuclear localization signal of $N F-\mathrm{kB}$ is exposed and the protein translocates into the nucleus, where it activates transcription factors and induces specific gene expression. In order to investigate the effects of PFOA on the activation of NF-kB signaling, which may be involved in cancer cell invasion induced by PFOA, immunofluorescence studies were performed to confirm whether PFOA promotes NF-kB nuclear translocation. Cellular nuclei were counterstained with Hoechst (shown in blue), whereas NF-kB p65 was stained green. Images of FTC133 cells showed that upon treatment, NF-kB p65 appeared to be distributed in the nucleus (Figure 3).

Involvement of $N F-\kappa B$ on cell invasion. Inhibition of phosphorylated NF-kB signaling protein by BAY 11-7085 was employed to confirm the role of $\mathrm{NF}-\mathrm{kB}$ in promoting the invasive ability of FTC133 cells. Treatment of FTC133 cells with $1 \mu \mathrm{M}$ BAY 11-7085 did not affect cell viability (data not shown). However, it significantly reduced the levels of phosphorylated NF-kB p65 compared to those without BAY 11-7085 (Figure 4A). In addition, after treatment with $1 \mu \mathrm{M}$ 
A

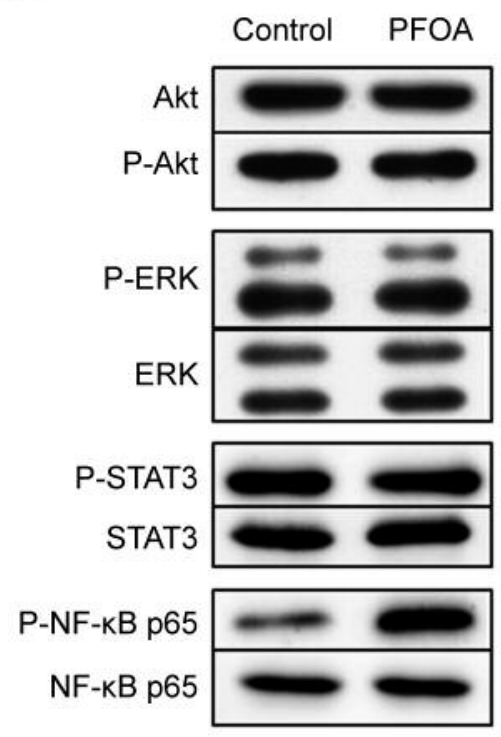

B

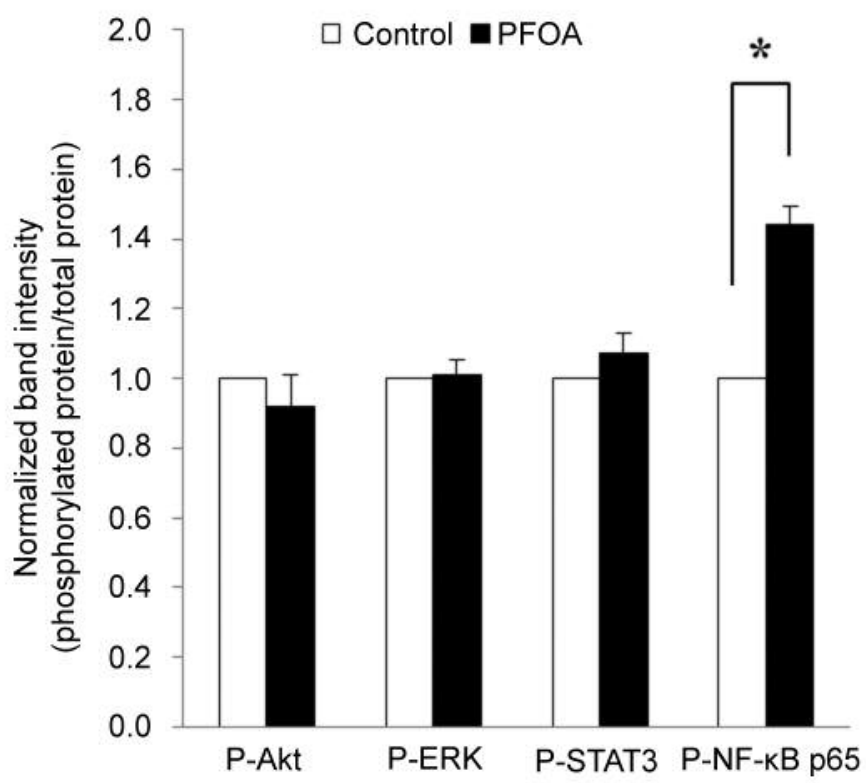

Figure 2. Effects of PFOA treatment on the expression of signaling proteins in FTC133 cells. Cells were incubated with $1 \mathrm{nM}$ PFOA or without PFOA for $72 \mathrm{~h}$, and then expression of proteins involved in signal transduction was analyzed by immunoblotting. A: Protein expression detected by immunoblot analysis. B: Normalization of band intensity of phosphorylated protein to that of the corresponding total protein. Data are presented as mean $\pm S D$ of three independent experiments. ${ }^{*} p<0.05$.

BAY 11-7085 followed by treatment with $1 \mathrm{nM}$ PFOA, the levels of phosphorylated NF-kB p65 expression were decreased by about $75 \%$. Treatment with BAY 11-7085 alone decreased also basal levels of phosphorylated NF-kB p65 by about $50 \%$. This indicates that NF-kB inhibitor (BAY 117085) could partially inhibit NF-kB p65 phosphorylation, even in the presence of PFOA (Figure 4B).

Next, we performed Transwell invasion assay to verify the involvement of NF-kB in cell invasion by treatment with BAY 11-7085. Our results indicate that the invasiveness of FTC133 cells, induced by PFOA, is significantly reduced to that of untreated control or cells treated only with BAY 117085 (Figure 4C). This suggests that PFOA activates FTC133 cell invasion through increased NF-kB activation, which correlates with the increased expression of NF-kB with increased cell invasiveness.

\section{Discussion}

PFOA is a ubiquitous compound that persists in the environment. Many studies have reported that PFOA can modulate cancer cell metastasis and thereby contribute to the enhanced aggressiveness of cancers (16). However, the effects and molecular consequences of PFOA exposure on thyroid cancer have not been elucidated. Thus, in this study, we investigated the effects of PFOA on follicular thyroid cancer cell metastasis and the underlying mechanism of PFOA-induced invasiveness.

Cell invasion is an indispensable event for metastasis, which allows tumor cells to move through the ECM barrier (7). PFOA treatment at various concentrations $\left(10^{-9}-10^{-4} \mathrm{M}\right) \mathrm{did}$ not affect FTC133 cell viability (data not shown), consistent with previous reports in various cancer cells (9). However, we showed that treatment with a low concentration of PFOA (1 $\mathrm{nM}$ ) had the ability to significantly enhance the invasiveness of FTC133 cells. This concentration is relevant as it is in the range of actual concentrations of PFOA found in human sera (6). These results indicate that PFOA showed effects on thyroid cancer invasiveness even at a low concentration.

However, cell invasion requires three major processes, namely cell migration, modulation of cell adhesion and proteolysis of ECM. Cell migration, assessed using a Transwell chamber with uncoated filter in the absence of Matrigel, indicated that PFOA did not show any significant effect on the migration of FTC133 cells. This indicates that PFOA has no effect on the mobility of the invaded cells. Since cancers undergo repetitive attachment-detachment to ECM during the invasion process, the effect of PFOA on FTC133 cell adhesion was determined. Our results showed that PFOA significantly increased cell adhesion to ECM, suggesting that PFOA increased the strength of attachment of thyroid cancer cells. 


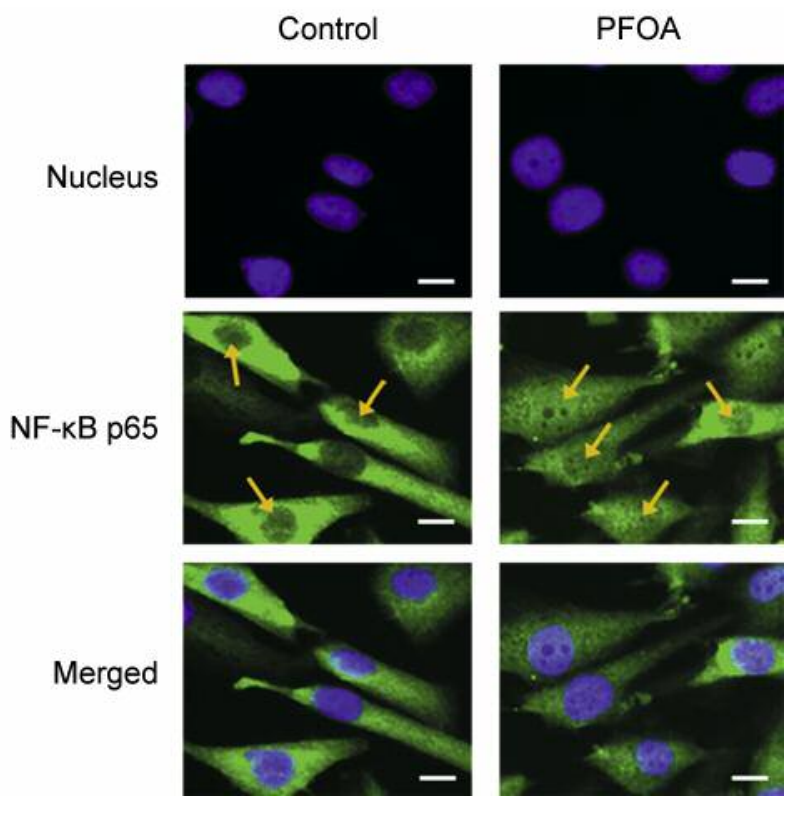

Figure 3. Effects of PFOA treatment on $N F-\kappa B$ nuclear translocation. Representative immunofluorescence images at 20x magnification of FTC133 cells upon treatment with $1 \mathrm{nM}$ PFOA for $72 \mathrm{~h}$. NF-kB p65 (Alexa Fluor $(R)$ 488-labeled, green) was distributed in the nucleus (Hoechst stain, blue) upon treatment, as labeled by solid yellow arrows. White bars represent length of $10 \mu \mathrm{m}$.

In order to facilitate invasion, cancer cells produce enzymes to degrade or remodel the ECM barriers. The major components of ECM include fibrous proteins, such as type IV collagens and elastins, adhesive glycoproteins such as laminin and fibronectin, and proteoglycans (17). One group of enzymes playing an important role in ECM-degradation is the MMPs. Among these, MMP-2 (72 kDa gelatinase) and MMP-9 (92 kDa gelatinase), which can efficiently degrade native type IV collagen, are well known to play critical roles in cancer progression and their expression levels were shown to increase with increasing malignancy potential of ovarian tumors (18, 19). Since it has been reported that MMP-2/-9 correlate with the invasion capability of cancer cells (20), the effects of PFOA on the enzymatic activity of MMP-2/-9 in FTC133 cells were determined using gelatin zymography. Our results revealed that PFOA could enhance the activity of only MMP-2 in FTC133 cells, as shown by clear bands at the molecular weight of 66 $\mathrm{kDa}$ for active MMP-2, without detecting MMP-9 activity. This could be attributed to the low levels of MMP-9 secreted from thyroid cancer cells. We can, therefore, infer that PFOAenhanced invasion is due to the increased activity of MMP-2.

It has been reported that expression of MMP-2/-9 is associated with the expression of $\mathrm{NF}-\mathrm{kB}$, an important transcription factor that controls several cellular responses including inflammation, invasion and cell survival (21). NF-kB
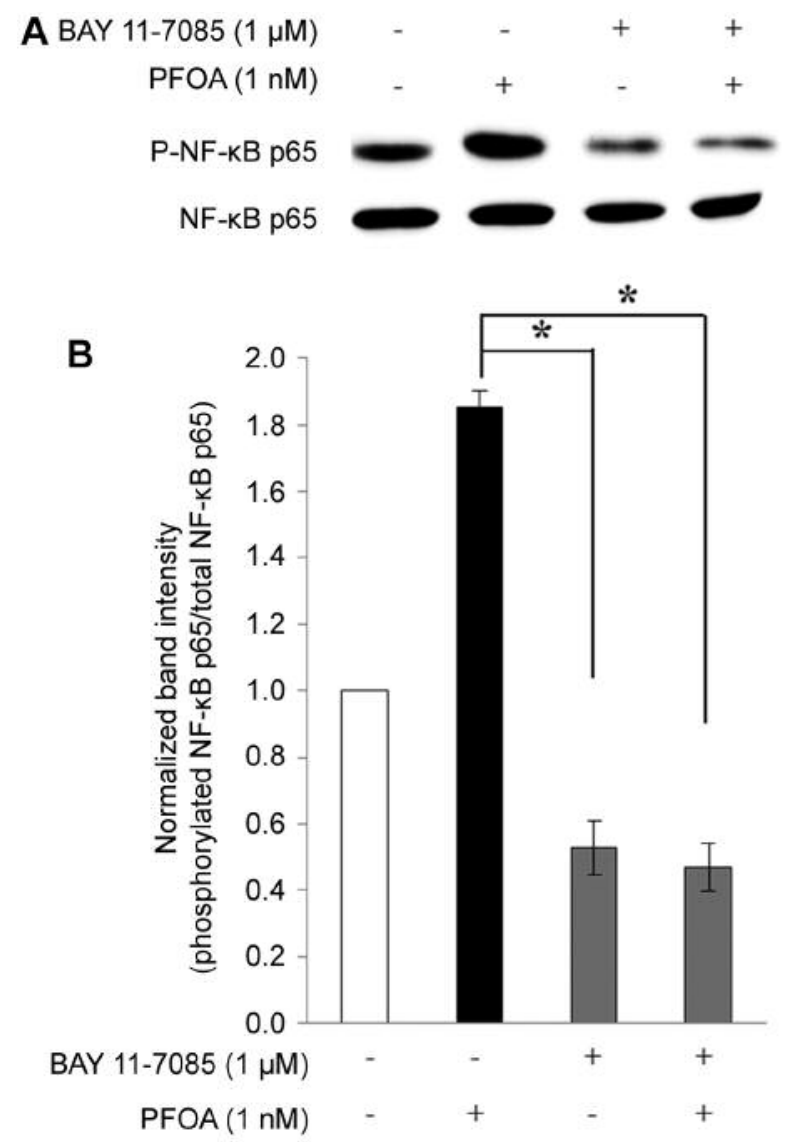

C

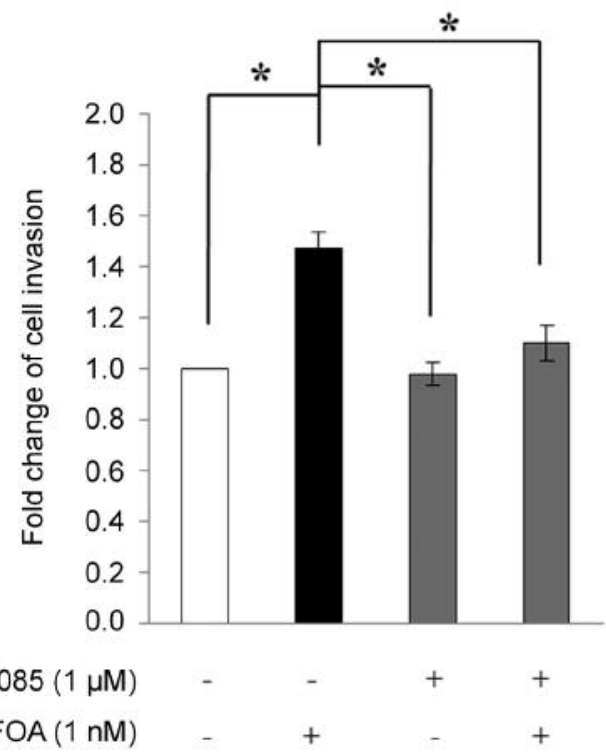

Figure 4. Involvement of NF-kB in PFOA-enhanced invasiveness of FTC133 cells. Cells were treated with $1 \mu M B A Y$ 11-7085, an inhibitor of $N F-k B$, for $1 \mathrm{~h}$, followed by treatment with $1 \mathrm{nM} P F O A$ for a total of 72 h. A: Protein expression detected by immunoblot analysis. B: Normalization of band intensity of phosphorylated protein to that of the corresponding total protein. C: Effect of BAY 11-7085 on PFOAenhanced invasiveness of FTC133 cells. Results are expressed as mean $\pm S . D$. from three independent experiments. ${ }^{*} p<0.05$. 
can be activated by pro-inflammatory cytokines, viral products, bacterial toxins and other stimuli (exogenous compounds, UV light, $\gamma$-radiation) (22). Once NF-kB becomes activated, it translocates from the cytoplasm to the nucleus where it binds target genes and initiates transcription. Previous studies have indicated that NF-kB activation contributes to the enhanced invasiveness of breast and colorectal cancer cells by regulating MMP-2 and MMP-9 expression $(9,10)$. Thus, we studied the effect of PFOA treatment on the activation of NF-kB signaling in FTC133 cells, and found that the enhancement in the PFOAinduced FTC133 cell invasion was accompanied by significantly increased phosphorylation of NF-kB, when compared to that of untreated control cells. Moreover, immunofluorescence assay showed that PFOA treatment promoted nuclear translocation of $\mathrm{NF}-\mathrm{kB}$. Our results demonstrated that PFOA induced NF-kB activation and translocation into the nucleus, which may contribute to the PFOA-enhanced invasiveness of FTC133 cells.

To further demonstrate this causative relationship, we studied the effect of BAY 11-7085 on the phosphorylation of NF-kB. BAY 11-7085 is an irreversible inhibitor of $\mathrm{IkB} \alpha$ phosphorylation that is generally used to block gene expression regulated through the classical pathway of NF-kB activation, such as inflammation (23). Inhibition of NF-kB/relA through the suppression of $\operatorname{IkB} \alpha$ phosphorylation, leading to a reduction in the formation of active $\mathrm{NF}-\mathrm{kB}$, has been shown to reduce tumor invasion and metastasis (24). Our results showed that treatment of FTC133 cells with BAY 11-7085 inhibited the phosphorylation of NF-kB that was induced by PFOA treatment. As a result, NF-kB activation and increased cell invasion were not observed in the presence of BAY 11-7085, suggesting that $\mathrm{NF}-\mathrm{kB}$ is involved in the enhanced invasiveness of FTC133 cells upon treatment with PFOA.

In conclusion, we demonstrated that PFOA can significantly promote the invasion of follicular thyroid cancer cells by inducing NF-kB activation and nuclear translocation. In addition, PFOA could stimulate the activity of MMP-2. Indeed, NF-kB activation contributed to the enhanced invasiveness of follicular thyroid cancer cells upon treatment with PFOA. These findings emphasize the toxic effects of PFOA even at a low concentration, which may lead to further investigations towards novel prevention and/or treatment strategies against the progression of follicular thyroid cancer.

\section{Conflicts of Interest}

The Authors declare no conflicts of interest regarding this study.

\section{Authors' Contributions}

P.S. performed all experiments and wrote the manuscript. K.L. contributed to data analysis and interpretation. J.S. provided critical revision of the manuscript. N.M.P. designed the experiments, implemented the research, wrote the manuscript and supervised this study. All Authors read and approved the final manuscript.

\section{Acknowledgements}

Funding was from the Chulabhorn Research Institute and Chulabhorn Graduate Institute. The Authors would like to thank to Dr. Benjaporn Homkajorn Songvasin from the Research Laboratory of Pharmacology, Chulabhorn Research Institute, for her assistance on the use of the fluorescence microscope.

\section{References}

1 D'Hollander W, de Voogt P, De Coen W and Bervoets L: Perfluorinated substances in human food and other sources of human exposure. Rev Environ Contam Toxicol 208: 179-215, 2010. PMID: 20811865. DOI: 10.1007/978-1-4419-6880-7_4

2 Jensen AA and Leffers H: Emerging endocrine disrupters: Perfluoroalkylated substances. Int J Androl 31(2): 161-169, 2008. PMID: 18315716. DOI: 10.1111/j.1365-2605.2008. 00870.x

3 Chen H, Zhang C, Han J, Yu Y and Zhang P: Pfos and pfoa in influents, effluents, and biosolids of chinese wastewater treatment plants and effluent-receiving marine environments. Environ Pollut 170: 26-31, 2012. PMID: 22763327. DOI: 10.1016/j.envpol.2012.06.016

4 Fromme H, Midasch O, Twardella D, Angerer J, Boehmer S and Liebl B: Occurrence of perfluorinated substances in an adult german population in southern bavaria. Int Arch Occup Environ Health 80(4): 313-319, 2007. PMID: 16915390. DOI: $10.1007 /$ s00420-006-0136-1

5 Corsini E, Avogadro A, Galbiati V, dell'Agli M, Marinovich M, Galli CL and Germolec DR: In vitro evaluation of the immunotoxic potential of perfluorinated compounds ( $\mathrm{pfcs}$ ). Toxicol Appl Pharmacol 250(2): 108-116, 2011. PMID: 21075133. DOI: 10.1016/j.taap.2010.11.004

6 Calafat AM, Wong LY, Kuklenyik Z, Reidy JA and Needham LL: Polyfluoroalkyl chemicals in the u.S. Population: Data from the national health and nutrition examination survey (nhanes) 2003-2004 and comparisons with nhanes 1999-2000. Environ Health Perspect 115(11): 1596-1602, 2007. PMID: 18007991. DOI: $10.1289 /$ ehp. 10598

7 Woodhouse EC, Chuaqui RF and Liotta LA: General mechanisms of metastasis. Cancer 80(8): 1529-1537, 1997. PMID: 9362419.

8 Ma Z, Liu X, Li F, Wang Y, Xu Y, Zhang M, Zhang X, Ying X and Zhang $\mathrm{X}$ : Perfluorooctanoic acid induces human ishikawa endometrial cancer cell migration and invasion through activation of erk/mtor signaling. Oncotarget 7(41): 66558-66568, 2016. PMID: 9362419.

9 Zhang W, Wang F, Xu P, Miao C, Zeng X, Cui X, Lu C, Xie H, Yin H, Chen F, Ma J, Gao S and Fu Z: Perfluorooctanoic acid stimulates breast cancer cells invasion and up-regulates matrix metalloproteinase-2/-9 expression mediated by activating nfkappab. Toxicol Lett 229(1): 118-125, 2014. PMID: 24960061. DOI: $10.1016 /$ j.toxlet.2014.06.004

10 Miao C, Ma J, Zhang Y, Chu Y, Li J, Kuai R, Wang S and Peng $\mathrm{H}$ : Perfluorooctanoic acid enhances colorectal cancer dld-1 cells invasiveness through activating nf-kappab mediated matrix metalloproteinase-2/-9 expression. Int J Clin Exp Pathol 8(9): 10512-10522, 2015. PMID: 26617761.

11 Maestri L, Negri S, Ferrari M, Ghittori S, Fabris F, Danesino P and Imbriani M: Determination of perfluorooctanoic acid and perfluorooctanesulfonate in human tissues by liquid chromato- 
graphy/single quadrupole mass spectrometry. Rapid Commun Mass Spectrom 20(18): 2728-2734, 2006. PMID: 16915561. DOI: $10.1002 / \mathrm{rcm} .2661$

12 Pirali B, Negri S, Chytiris S, Perissi A, Villani L, La Manna L, Cottica D, Ferrari M, Imbriani M, Rotondi $M$ and Chiovato L: Perfluorooctane sulfonate and perfluorooctanoic acid in surgical thyroid specimens of patients with thyroid diseases. Thyroid 19(12): 1407-1412, 2009. PMID: 20001722. DOI: 10.1089/ thy.2009.0174

13 Coperchini F, Pignatti P, Lacerenza S, Negri S, Sideri R, Testoni C, de Martinis L, Cottica D, Magri F, Imbriani M, Rotondi M and Chiovato L: Exposure to perfluorinated compounds: In vitro study on thyroid cells. Environ Sci Pollut Res Int 22(3): 2287-2294, 2015. PMID: 25182428. DOI: 10.1007/s11356-014-3480-9

14 Jantaree P, Lirdprapamongkol K, Kaewsri W, Thongsornkleeb C, Choowongkomon K, Atjanasuppat K, Ruchirawat S and Svasti $\mathrm{J}$ : Homodimers of vanillin and apocynin decrease the metastatic potential of human cancer cells by inhibiting the fak/pi3k/akt signaling pathway. J Agric Food Chem 65(11): 2299-2306, 2017. PMID: 28248106. DOI: 10.1021/acs.jafc.6b05697

15 Chiablaem K, Lirdprapamongkol K, Keeratichamroen S, Surarit $\mathrm{R}$ and Svasti J: Curcumin suppresses vasculogenic mimicry capacity of hepatocellular carcinoma cells through stat 3 and pi3k/akt inhibition. Anticancer Res 34(4): 1857-1864, 2014. PMID: 24692720.

16 Pierozan P, Jerneren F and Karlsson O: Perfluorooctanoic acid (pfoa) exposure promotes proliferation, migration and invasion potential in human breast epithelial cells. Arch Toxicol 92(5): 17291739, 2018. PMID: 29502166. DOI: 10.1007/s00204-018-2181-4

17 Pass HI: Biology of metastatic disease. Semin Thorac Cardiovasc Surg 14(1): 10-17, 2002. PMID: 11977012.

18 Kallakury BV, Karikehalli S, Haholu A, Sheehan CE, Azumi N and Ross JS: Increased expression of matrix metalloproteinases 2 and 9 and tissue inhibitors of metalloproteinases 1 and 2 correlate with poor prognostic variables in renal cell carcinoma. Clin Cancer Res 7(10): 3113-3119, 2001. PMID: 11595703.
19 Stamenkovic I: Matrix metalloproteinases in tumor invasion and metastasis. Semin Cancer Biol 10(6): 415-433, 2000. PMID: 11170864. DOI: $10.1006 /$ scbi.2000.0379

20 Pereira AM, Strasberg-Rieber M and Rieber M: Invasionassociated mmp- 2 and mmp-9 are up-regulated intracellularly in concert with apoptosis linked to melanoma cell detachment. Clin Exp Metastasis 22(4): 285-295, 2005. PMID: 16170665. DOI: $10.1007 / \mathrm{s} 10585-005-8672-8$

21 Adya R, Tan BK, Chen J and Randeva HS: Nuclear factor-kappab induction by visfatin in human vascular endothelial cells: Its role in mmp-2/9 production and activation. Diabetes Care 31(4): 758760, 2008. PMID: 18184904. DOI: $10.2337 / \mathrm{dc} 07-1544$

22 Baldwin AS Jr.: The nf-kappa b and i kappa b proteins: New discoveries and insights. Annu Rev Immunol 14: 649-683, 1996. PMID: 8717528. DOI: 10.1146/annurev.immunol.14.1.649

23 Strickson S, Campbell DG, Emmerich CH, Knebel A, Plater L, Ritorto MS, Shpiro N and Cohen P: The anti-inflammatory drug bay 11-7082 suppresses the myd88-dependent signalling network by targeting the ubiquitin system. Biochem J 451(3): 427-437, 2013. PMID: 23441730. DOI: 10.1042/BJ20121651

24 Yan M, Xu Q, Zhang P, Zhou XJ, Zhang ZY and Chen WT: Correlation of nf-kappab signal pathway with tumor metastasis of human head and neck squamous cell carcinoma. BMC Cancer 10: 437, 2010. PMID: 20716363. DOI: 10.1186/1471-2407-10-437

Received March 22, 2019

Revised April 10, 2019

Accepted April 11, 2019 